\title{
Ramón Pérez Costales, en las dos versiones de un cuento de Emilia Pardo Bazán
}

\author{
José Manuel González Herrán \\ (UNIVERSIDADE DE SANTIAGO DE COMPOSTELA) \\ josemanuel.gonzalez.herran@usc.es
}

(recibido setembro/2019, aceptado novembro/2019)

RESUMEN: El 29 de octubre de 1910 en la revista bonaerense Caras y Caretas se publica un cuento de Emilia Pardo Bazán titulado" Auténtico". Dos años más tarde, en su volumen Cuentos trágicos, la escritora coruñesa incluye "Argumento", versión bastante modificada del aparecido en Caras y Caretas. Entre ambas publicaciones ha fallecido en A Coruña, el 18 de enero de 1911, Ramón Pérez Costales, médico personal y amigo de doña Emilia, que, como es bien sabido, fue el modelo del Doctor Moragas en La piedra angular (que aparece también en otras novelas y cuentos de la autora). Según mi hipótesis, también lo habría sido para el Doctor Zutano de este relato; y las notables diferencias que hay entre sus dos versiones se deberían precisamente al fallecimiento de aquel médico.

PALABRAS CLAVE: Ramón Pérez Costales, Emilia Pardo Bazán, cuentos.

ABSTRACT: On October 29, 1910, a story by Emilia Pardo Bazán entitled "Auténtico" is published in the Buenos Aires magazine Caras y Caretas. Two years later, her volume Cuentos trágicos, includes "Argumento", a version, quite modified from the one in Caras y Caretas. Between both publications he died in A Coruña, on January 18, 1911, Ramón Pérez Costales, personal physician and friend of Mrs. Emilia; which, as is well known, was the model of Doctor Moragas in La piedra angular (wich also appears in other novels and tales of the author). According to my hypothesis, it would also have been for Doctor Zutano of this story; and the notable differences between its two versions are due precisely to the death of that doctor.

KEY WORDS: Ramón Pérez Costales, Emilia Pardo Bazán, cuentos.

En mi ponencia "La cuestión social en algunos cuentos de Emilia Pardo Bazán", presentada en un coloquio en la Casa de Velázquez, de Madrid, en 2013 (publicada en González Herrán 2014), sugerí que el protagonista de la anécdota en que se basaba uno de ellos bien pudo ser Ramón Pérez Costales, ovetense de nacimiento y coruñés de residencia, amigo y médico personal de doña Emilia Pardo Bazán y su familia. La reciente publicación de un interesante estudio (Ventureira Novo y Pardo Antequera 2019) sobre 
Pérez Costales y el joven Picasso -de quien fue protector y primer mecenas en su etapa coruñesa- me anima a volver sobre aquella hipótesis, que espero confirmar, apoyándome, entre otras razones, en el cotejo textual apuntado en 2013 y que aquí amplío.

Pero antes recordemos sumariamente algo muy conocido en el pardobazanismo: nuestra autora se habría inspirado en aquel médico para uno de los principales personajes de su novela La piedra angular $(1891)^{1}$, que aparece también en otras (Doña Milagros, 1894; Memorias de un solterón, 1896; La Quimera, 1905) y en algunos cuentos ("Planta montés", 1890; "La bronceada", 1902), siempre con el nombre ficticio de Pelayo Moragas²; también -si tengo razón en mi propuesta- como el doctor Zutano del relato que aquí comentaré.

Aunque la peripecia vital, la carrera política y la relevancia social de Ramón Pérez Costales son bien conocidas ${ }^{3}$, carecemos de un estudio monográfico que se ocupe no solo de su relación con la escritora, sino -sobre todo- de su pertinencia y relevancia como "modelo vivo" del personaje literario. A la espera del trabajo que demando, conviene recordar ahora aquellos rasgos del individuo que caracterizan también al personaje (se Ilame Moragas o Zutano); para ello, nos serviremos de la semblanza que la propia escritora

\footnotetext{
1 Aunque sin mencionar expresamente a su modelo, la propia autora, en carta a Giner de los Ríos (sin fecha, pero que con toda seguridad es de principios de 1892, recién aparecida la novela), señaló que Moragas tenía un referente real y próximo a ella: "Moragas en cambio existe, y esa mezcla de guasa y filantropía se la he visto yo emplear" (Varela Iglesias 2001: 475). Según creo, fue Carmen Bravo la primera en identificarlo: "El tipo de médico que aparece en este libro y que tan importante papel desempeña en el curso de la novela es el vivo retrato de don Ramón Pérez Costales, que asistió a la Pardo Bazán en el nacimiento de sus tres hijos y que era el médico de cabecera de la familia" (Bravo-Villasante 1962: 186); luego lo han repetido Varela Jácome 1973: 133, Clemessy 1973: 223, y, en general, todos los que han editado o estudiado las novelas en que aparece Moragas.

2 Nadie se ha planteado -que yo sepa- por qué doña Emilia eligió ese apellido, tan raro en Galicia como frecuente en Cataluña; se me ocurren dos muestras, acaso pertinentes aquí: el escritor Narcís Oller i Moragas (con quien doña Emilia mantuvo frecuente correspondencia desde 1882); pero también Estanislao Figueras i Moragas, uno de los presidentes de la Primera República, en la que Pérez Costales llegó a ser Ministro de Fomento, bajo la presidencia de Pi i Margall.

3 Nacido en Oviedo en 1832, estudió Medicina en las Universidades de Oviedo, Madrid y Santiago de Compostela, donde se licenció en 1854. Tras ejercer como médico en Toledo, en 1858 se instala en A Coruña. En 1866 ingresa en el Cuerpo de Sanidad Militar, pero, a causa de la represión posterior a la insurrección del cuartel de San Gil (militante del Partido Republicano Federal de Pi i Margall, había formado parte de una de las conspiraciones contra Isabel II), se exilia a Portugal, donde reside hasta que, con el destronamiento de aquella reina en 1868, regresa a la capital coruñesa. En 1872 es elegido diputado a Cortes; al año siguiente, vuelve a ser elegido, para las constituyentes de la Primera República. En junio de ese mismo año es nombrado Ministro de Fomento en el gobierno que preside Pi i Maragall, puesto que ocupa durante tres semanas. Regresa a Coruña donde, sin abandonar su actividad política, lleva a cabo una importante actividad humanitaria: con el dinero de su cesantía como Ministro, funda una escuela de párvulos, abre un instituto de vacunación, participa en la fundación de la "Cocina Económica", de la que llega a ser Presidente. También lo fue del Colegio de Médicos, de la Academia de Medicina y Cirugía, cofundador -con Emilia Pardo Bazán-y Vicepresidente de la Sociedad del Folklore Gallego, germen de la futura Academia Galega, de la que fue nombrado Académico honorario. Falleció en A Coruña en 1911 (cfr. Barreiro Fernández 2003: 504-506; De la Fuente Monge 2009; Fraga Vázquez, 2013; Hernández Segura 2001; Leirós Fernández 2010-2011; Moreno González 1974; Murguía 1911; Santiso Rolán y González Prieto 2015; “Cronología: Costales-Picasso, con la colaboración de Xosé Crisanto Gándara Eiroa”, en Ventureira Novo y Pardo Antequera 2019: 125-140).
} 
hacía en su prólogo a Perucho. Poema en seis cantos (Pérez Costales 18874); entre otras cosas, allí leemos:

Es Don Ramón Pérez Costales una personalidad multiforme, curiosa y simpática desde cualquiera de sus aspectos. Hombre de ciencia, ante todo y sobre todo, su tino médico, sus incesantes estudios, su afortunadísima práctica, le hubieran colocado, si residiese en Paris, a la altura de los Charcot y Faccoud.

\section{(...)}

Otro impedimento pudo estorbarle llegar a ser el médico eminente, serio e inspirado que es, a saber: su afición incontrastable a las luchas políticas (...) La idea federativa, que no quiero calificar aquí para no darle una desazón al Señor Costales, jamás tuvo adalid más resuelto, ni más ardiente propagandista; y la República española no poseyó Ministro responsable más desinteresado y benéfico, puesto que su cesantía se empleó y emplea en sostener un precioso Asilo-escuela de párvulos, fundado y organizado por el mismo generoso mantenedor

(...)

Fue siempre un entusiasta que amó la revolución "poemáticamente", con el sentimentalismo propio de un carácter abierto y noble, que se compadece de las miserias y dolores del pueblo y desea extirparlas de un solo tajo de bisturí, ni más ni menos que si fuesen algún quiste (Pardo Bazán 1887: ix-xi).

De esa semblanza, me importa destacar ahora determinados aspectos que, como han notado los estudiosos de la obra pardobazaniana, caracterizan también al ficticio doctor Moragas: su curiosidad e interés por los avances científicos ${ }^{5}$; su afición por la lucha política, desde una postura republicana y federal; su filantropía en la práctica médica y en su actuación social ${ }^{6}$; su interés por la educación y las nuevas teorías pedagógicas ${ }^{7}$; incluso -aunque aquí la escritora lo use como metáfora- su destreza en el manejo del bisturí para extirpar un quiste... Rasgos biográficos, ideológicos y de personalidad que se repiten

\footnotetext{
4 Se puede acceder a una reproducción facsímil de esa edición en: http://biblioteca.galiciana.gal/pt/consulta/ registro.cmd?id=6888; también en: $\underline{\text { http://bdh-rd.bne.es/viewer.vm?id=0000210248\&page=1 }}$ [consultado: agosto 2019]

5 Cfr. en La piedra angular: "Cuando podía lograr tanta fortuna, dedicaba la noche a leer de política o de ciencia, sobre todo de aquellas cuestiones palpitantes de la moderna medicina que llevan involucrado algún problema metafísico, algún misterio del espíritu, alguna generalización filosófica. Si Moragas estudiaba por obligación la medicina curativa, por recreo andaba siempre a vueltas con los mal conocidos resultados de la sugestión, con las revelaciones de la frenopatía y con los efectos de ciertas substancias tóxicas sobre el cerebro humano. Gustábale mucho el estudio de las que llamaban nuestros padres enfermedades mentales, y era franco admirador de los médicos modernos que aplican atrevidamente a los problemas del orden moral el método positivo y analítico de la ciencia presente. Como de esto se escribe mucho en el día, y Moragas lo hacía venir todo de París en grandes remesas, sus orgías de lectura tenían el retiro de la Erbeda por testigo y cómplice” (Pardo Bazán 1999: 455).
}

${ }^{6}$ Cfr. en La piedra angular: "Moragas luchaba consigo mismo; no entre encontrados sentimientos, que es lucha fácil, casi elemental, sino entre sentimientos análogos, todos amasados con aquella generosidad semiquijotesca y semifilantrópica que, diga lo que quiera el vulgo, no está reñida con las tendencias positivas del científico"; en Memorias de un solterón: “el filántropo Doctor Moragas (...) Le pediré a Moragas ese dinero, y aunque por su genio caritativo tiene mil compromisos, de seguro me lo da" (Pardo Bazán 1999: 467-468 y 917, respectivamente).

7 En una carta a Giner de los Ríos, y a propósito de sus conocimientos sobre nuevos métodos de enseñanza, Emilia Pardo Bazán alude a "una serie de artículos que en un periódico de Santiago publiqué, encomiando la organización de la Escuela de Párvulos que fundó aquí [A Coruña] Costales” (Varela Iglesias 2001: 366). 
-más bien, se modulan- en el doctor Zutano que protagoniza los relatos "Auténtico" y "Argumento": dos textos que, como enseguida veremos, no son sino dos versiones, algo modificadas, de un mismo relato (Pardo Bazán 1910; Pardo Bazán 1912). ${ }^{8}$

El segundo de ellos era bien conocido (y sigue siendo apreciado ${ }^{9}$ ) desde su aparición en el volumen Cuentos trágicos (1912), sin que hubiese noticia de su publicación previa en la prensa periódica; situación que se modificó cuando rescaté en la revista Siglo diecinueve once cuentos pardobazanianos, aparecidos en la revista bonaerense Caras y Caretas entre 1909-1916 (González Herrán 2010), olvidados hasta entonces. Aunque no todos: el titulado "Auténtico", aparecido en la entrega correspondiente al 29 de octubre de 1910, es, sin duda, una versión anterior del que luego se titularía "Argumento"; el hecho de que no nos conste la edición previa en la prensa periódica de ningún relato así titulado bien puede indicar que, para incluirlo en su libro de 1912, la autora recogió el publicado en Caras y Caretas, modificando no solo su título, sino buena parte del texto.

Su asunto es muy simple: un obrero acude con su hijo, gravemente enfermo, a la consulta de un médico que, además de su reconocido prestigio, es famoso por su desinteresada atención hacia los pobres ${ }^{10}$. La dolencia del muchacho es grave y requiere una urgente intervención quirúrgica, que el galeno hará en su consulta; cuando está en plena operación, el cirujano -conocedor de que en estos días el obrero está en huelga- la interrumpe, pues él también quiere ejercer su "sagrado derecho a la huelga". Enseguida veremos cómo se resuelve tan dramática situación...

Tal como parecía sugerir el título de la versión en Caras y Caretas, la historia recrearía un sucedido verídico (del que acaso podría haber otros testimonios), conocido y repetidamente contado, sobre todo en los medios sociales opuestos a la huelga. Más aún: me atrevo a sugerir no solo -como hice en mi ponencia de 2013-que el médico de aquel relato ("Ilamémosle el doctor Zutano", reiteran ambas versiones en su comienzo) estaba inspirado en Pérez Costales, sino que acaso él mismo habría protagonizado aquella anécdota, u otra muy similar, que, sin duda, referiría a sus más próximos, como doña Emilia; y que, por tanto, podría ser conocida de los lectores coruñeses. De ahí el título, que trata de ponderar lo auténtico del sucedido. ¿Por qué, cuando lo recoge en Cuentos trágicos, la autora lo cambia, soslayando aquella autenticidad (tal vez dudosa, o indemostrable), para insistir en el poder convincente de esa historia -con los razonamientos del médico protagonista-, como argumento contrario a la huelga?

\footnotetext{
8 En lo que sigue, transcribo, resumo o parafraseo de González Herrán 2014: 170-176.

9 Véase, por ejemplo, el comentario "El médico altruista que declaró su derecho a la huelga", fechado el 16 de octubre de 2017, en el blog Medicina y Melodía: https://medymel.blogspot.com/2017/10/el-medico-altruistaque-declaro-su.html [consultado: agosto 2019].

10 En cierta medida y como tendré ocasión de notar más adelante, la situación (el médico, el padre, el hijo enfermo) recuerda la que se produce en el capítulo VII de La piedra angular.
} 
Creo que, entre otras, puede haber razones relacionadas con las fechas y los lugares de aparición de ambas versiones ${ }^{11}$, porque algo muy importante ocurre en ese lapso: el 18 de enero de 1911 fallece en su domicilio coruñés Ramón Pérez Costales. En consecuencia, la publicación de "Auténtico", el 29 de octubre de 1910 en Caras y Caretas, se produce cuando el médico aún vivía, aunque ya retirado de la vida profesional y social, desde que en junio de 1902 hubiese sufrido un ataque de hemiplejia. Al año siguiente de su muerte, en 1912, aparecerá en Madrid el volumen Cuentos trágicos, que muy probablemente la escritora estuvo preparando en los meses precedentes; tarea que consistía no solo en seleccionar relatos entre los previamente publicados en periódicos y revistas, sino también, como en otro lugar he demostrado (González Herrán 2013), en su minuciosa lectura, revisión, cuidadosa corrección y -con frecuencia- notables modificaciones textuales. En lo que sigue explicaré las muchas variantes existentes entre "Auténtico" y "Argumento"; cambios tan abundantes y notables que constituyen una verdadera reescritura del texto aparecido en la publicación bonaerense. Como espero mostrar, aparte de por razones estéticas o estilísticas ${ }^{12}$, tales cambios pueden ser debidos al reciente fallecimiento de quien habría protagonizado aquella ejemplar anécdota.

Ya expliqué antes la modificación en el título (de la autenticidad del suceso a su poder persuasivo en el debate sobre las huelgas). Veamos ahora, siguiendo el curso de ambos textos, algunas de las demás diferencias que se advierten entre ellos. La primera, ya en las líneas iniciales, trata de diluir la localización coruñesa y gallega del suceso ("¿Quién no le conoce, no en la ciudad, en las cuatro provincias y aún más allá, ultrapuertos?", leemos en la primera versión), para dejarlo en un indeterminado ámbito provinciano: “¿Quién no conoce a aquel médico, no solo en la ciudad, sino en la provincia y aún en Madrid, al que desdeña profundamente?". Notemos, además, que este añadido -el profundo desdén por la capital del reino- se amplía en la segunda versión; lo que en la primera era una mera

\footnotetext{
11 Lugares que no solo son Buenos Aires y Madrid: “Auténtico" vuelve a aparecer, con levísimas y poco significativas variantes respecto a la publicada en Caras y Caretas, en el Diario de la Marina, de La Habana, en dos partes, que corresponden a los días 27 y 28 de diciembre de 1912; es decir, cuando ya había aparecido en Madrid el volumen Cuentos trágicos, donde se recogía "Argumento". Tal vez, por publicarse en La Habana, a la autora no le preocupaba demasiado que el personaje ficticio recordase a su amigo médico, fallecido en A Coruña casi dos años antes.

12 Así, por ejemplo, se alivia el tono desgarrado de la primera versión, suprimiendo -porque acaso parecían demasiado "naturalistas"- las frases que presentaban al niño enfermo y a su violento padre: "De la garganta entrapajada de la criatura salía un estertor ronco, de asfixia, y su cabeza, inerte, se apoyaba en el hombro del padre. Este, apretando los dientes para contener la impaciencia, aguardaba, deseoso de aniquilar de un puñetazo a los que le aventajaban en turno". O esta descarnada pintura de los gestos y comentarios del médico ante el estado del niño: "fue levantando los guiñapos fétidos que envolvían el cuello del enfermo, bajando la camisa, despojándole del raído chaquetón. Las carnes demacradas y sucias aparecían”.
} 
alusión a "los honorarios modestos que reclama"13 cargada de connotaciones cuasi religiosas:

Son muchas las cosas que desdeña, y entre ellas, el dinero. Lo desdeña con sinceridad, sin alharacas. Podría ser rico; su fama de mago, más que de hombre de ciencia, le permitiría exigir fuertes sumas por las curas increíbles que realiza; pero para él existen la conciencia, el alma, la otra vida -un sinnúmero de cosas que mucha gente suprime por estorbosas y tiránicas-, y se limita a tomar lo que basta al modesto desahogo de su existir. No tiene coche, ni hotel, ni cuenta corriente en el Banco.

Significativas son también las correcciones que afectan a la caracterización del médico; la versión de 1910 destacaba lo sorprendente de su comportamiento: "La fama de su ciencia, o más bien de sus geniales aciertos y de sus rarezas típicas, va adquiriendo proporciones de leyenda. Se tiene en él no confianza, fe ciega y también inspira terror (...) Infunde miedo por sus desplantes, por sus ironías, por su segunda vista, de escocés, por sus burlas, por sus regaños, por su originalidad, por lo imprevisto de sus prescripciones". En cambio, el texto de 1912 da una imagen menos pintoresca, más ejemplar y más cristiana ("espera tener un lugar en el cielo, al lado de los médicos que hayan cumplido con su deber de cristianos, que algunos hay, y hasta en el Santoral los encontramos, con su aureola y todo").

Parece evidente la intención de dibujar con tintes más favorables al personaje, que en la versión de la revista argentina parecía algo caricaturizado; así, por ejemplo, donde aquella decía "rendido de cansancio, a horas irregulares, el médico da una orden furibunda: "A largarse todos»", en el libro de 1912 leemos: "rendido de cansancio, necesitando ya reparar las fuerzas con frugal almuerzo, da por terminada la faena del día". Otras veces, la matización es más sutil. "Su acción rápida forma parte de su genialidad. Además cree que generalmente son una farsa los preparativos, las precauciones... -¡Bah, bah! Farolerías", escribía en 1910; en 1912 lo explica y argumenta: "-Tanto aparato, tanto aparato para cosas tan sencillas -repite, despreciativo, burlándose un poco de la escenografía científica, que no se hizo para él-. ¡Bah, bah! Las cosas, a la pata la llana”.

Por lo que se refiere a sus ideas políticas y sociales, es interesante advertir cómo ciertas frases que en la versión primera notaban lo radical y casi anarquista de sus posturas

El doctor Zutano en nada se parece a un reaccionario clásico. Amparador de los desheredados, a toda hora les tiene dispuesto el socorro de su ciencia. De los poderosos no hace caso alguno. A las damas emperifolladas las pone como un renegrido trapo. No le impresionan, al contrario, le provocan cierto espíritu agresivo y frondista los personajes políticos y los plutócratas. A la aristocracia de sangre no la mira tan mal, porque hijo del pueblo, un marqués le ayudó en su carrera ${ }^{14}$. Sin embargo, sospecho que no cree en sangres azules. Para él, los hombres son hombres tan solo; hombres que

\footnotetext{
14 Según me confirma Xosé Crisanto Gándara Eiroa, el más cualificado investigador sobre Ramón Pérez Costales (ayuda que aquí reconozco y agradezco), no hay ningún dato que nos permita suponer que él hubiese recibido una ayuda similar para realizar sus estudios, sucesivamente en el Colegio de los Escolapios de Zaragoza, en el Instituto de Toledo y en las Universidades de Oviedo, Santiago y Central de Madrid.
} 
padecen. Iguales todos, con la única igualdad suprema; carne doliente ahora, polvo y ceniza mañana...

al pasar al libro muestran una explicación algo más matizada y tolerante: "A los poderosos de la tierra no los conoce sino cuando sufren, cuando son mísera carne enferma, iguales al menesteroso ante el dolor (...) Ni los personajes políticos, ni los aristócratas, ni los plutócratas impresionan al doctor". Incluso es perceptible lo que antes apunté como visión más cristiana de su pensamiento: el concepto de la humanidad que expresaba en 1910 "carne doliente ahora y ceniza mañana...", se complementa así en 1912: "Humanidad doliente ahora, polvo y ceniza mañana, excepto la luminosa partícula, el espíritu, que dará cuenta y será responsable ante la justicia inmanente..."

Ese aspecto del relato -su dimensión política y social- adquiere una especial relevancia si consideramos la biografía del modelo. En la versión primera se afirmaba que "la farándula política inspira desprecio al doctor, venga de arriba o venga de abajo": algo que puede sorprender si consideramos la dilatada carrera política de Pérez Costales, pero que se entiende mejor a la altura de 1910, tras algunos fracasos y decepciones sufridas en los últimos años de su vida (cfr. De la Fuente Monge 2009; Hernández Segura 2001; Moreno González 1974). Pues bien, aquella sucinta declaración ("la farándula política inspira desprecio al doctor") se concreta y amplía en la versión de 1912: "Detesta la agitación política. No conoce más ley que el trabajo. Nadie menos «burgués» y, sin embargo, nadie más enemigo de las huelgas, los meetings, las arengas y las luchas electorales. "Pillos que holgazanean y pillos que medran.» Tal es su definición, de la cual nadie le saca."

No estoy seguro de que el antiguo Ministro de la República (pese a aquellos desengaños y traiciones) suscribiese esa "definición" que pone la autora en labios del doctor Zutano; pero la coherencia interna del relato exige ese tipo de argumentos, para preparar y justificar su reacción cuando se entera de que el padre del niño enfermo es un huelguista. En todo caso, y a propósito de la actitud del médico ficticio respecto al movimiento obrero, conviene recordar el episodio que cuenta uno de los biógrafos de Pérez Costales:

Desde principios de año [1872] la Internacional va consiguiendo adeptos en las masas, de modo que el 17 de julio los obreros de la ciudad deciden abandonar el republicanismo, proclamar la propiedad colectiva y la anarquía. Un mes después, tras las elecciones de agosto, en las que Pérez Costales había sido elegido diputado, sufre un intento de agresión por un grupo de obreros de la Internacional. El suceso tuvo amplia difusión en la prensa y en los círculos políticos. Fue aprovechado por los internacionalistas para atacar al partido republicano federal $y$, personalmente, al propio Pérez Costales, mediante folletos como "El zapatero y el Médico" y hojas sueltas, como la publicada por el obrero Pedro Chas, en verso" (Moreno González 1974:187-189). ${ }^{15}$

\footnotetext{
$\overline{15}$ En estos términos lo resume De la Fuente Monge (2009): “Tras ser reelegido diputado en agosto de 1872, los obreros internacionalistas de La Coruña intentaron agredir y desprestigiar al popular «médico Costales», con varios pasquines y el folleto El Zapatero y el Médico, lo que hizo que, sintiéndose un republicano honrado y redentor del pueblo trabajador, se plantease abandonar la política".
} 
Con tales antecedentes resultan más comprensibles los términos en que se desarrolla la conversación sobre la huelga que mantienen el obrero y el médico en la versión de Caras y Caretas:

$-(\ldots)$ Ahora estamos en huelga.

Plantóse el médico. Su mirada brillante y sagaz escrutaba el rostro de su interlocutor.

-Huelga... ¿voluntaria? ¿O es que le falta quien le dé labor?

-No, señor, no es eso... A mí, como faltarme, nunca me ha faltado... Estamos en huelga hace cinco meses, para conseguir ciertas ventajas.

-¡Arrea! ¡Chacho! -articuló, con tuteo repentino- cinco meses que descansas, y yo, todas las mañanas, me rompo la cabeza aquí: ¿Y no conoces que con esa huelga perjudicas a los otros... vamos, a los fabricantes, a los industriales, que también tendrán obligaciones, familia, hijos?

Un expresivo encogimiento de hombros fue la respuesta, con lacónica frase: - La huelga es un derecho.

-Bien; tenéis la cabeza de cemento, y el corazón de no sé qué, jadelante!

En el texto de 1912 el diálogo es más escueto; el médico no argumenta, pero su gesto permite suponer su postura:

-Soy carpintero de armar... Pero ahora estamos en huelga.

- ¿En huelga? -preguntó severamente el médico, frunciendo el ceño y clavando el mirar en la cara del cliente.

-Sí, señor... Eso no es cosa mala... Como usted me enseña, con la huelga nos defendemos de los patronos. Ejercemos un sagrado derecho.

-Bueno, bueno... ¿En huelga, eh? Pues venga esta tarde. Le espero.

La intención (a mi juicio, evidente) de la autora por dibujar con rasgos más positivos el pensamiento del médico ficticio, por respeto a la memoria de su modelo, no se limita a estas modificaciones en sus palabras, sino también -y más- en otro cambio más sutil e importante, que afecta al comportamiento del personaje ( $y$ a la temporalidad del relato): en "Auténtico", la consulta e intervención quirúrgica se desarrolla en una única sesión, de modo que el sorprendente comportamiento del médico parece una respuesta inmediata -acaso irreflexiva- ante los argumentos del huelguista. En cambio, "Argumento" divide la situación en dos momentos: tras la primera consulta matinal, donde el médico diagnostica la dolencia y el obrero explica cómo y por qué está en huelga, la necesaria intervención tendrá lugar por la tarde. Con ello, además de preparar al lector para una situación impresionante, hace más verosímil -por meditado- el gesto del cirujano.

También en lo que se refiere a la dolencia del muchacho y la cirugía posterior podemos notar una leve modificación, que no creo gratuita. En la versión primera se trata de "un tumor interior, en la garganta", que es preciso extraer; la segunda versión del relato no localiza la dolencia ("el chiquillo padece un tumor..., bueno, un bulto..., no le importa a usted dónde..., dentro, ¿me entiende?, y hay que quitárselo, iy cuanto antes!"), aunque la cirugía parece situarlo en el tórax: "Con la celeridad asombrosa que le caracteriza, abrió de un seguro tajo el costado, por la espalda, y fue ensanchando la incisión y aislando el 
tumor para extraerlo". Como posible explicación para ese cambio se me ocurre recordar algo que la autora había escrito, refiriéndose al médico de La piedra angular: “Moragas, el mayor padrazo de Marineda, el enamorado de la niñez, el derrochador de juguetes y confites, el hombre que después de una traqueotomía había mezclado sus lágrimas con las de la familia de la operada criatura!" (Pardo Bazán 1999: 469); si, como supongo, la escritora coruñesa evocaba con ese comentario un episodio -acaso bien conocido entre sus más próximos- protagonizado por el médico que servía de modelo al personaje, ahora, en la reescritura del relato, prefiere difuminar o borrar una referencia tan concreta e identificable.

Llegamos así al momento crucial de la historia, cuando, en plena intervención quirúrgica, el médico la interrumpe. Lo que en el texto de 1910 se produce "de súbito" y justificado de inmediato ("Me declaro en huelga"), en 1912 se muestra de modo gradual, y por ello, más sorprendente: "he aquí que el doctor suspende su trabajo, levanta el bisturí... y, sentándose cerca de la ventana, coge un libro y se pone a leer tranquilamente".

A partir de aquí las dos versiones resuelven la situación de manera sutilmente diferente, de modo que el sentido de la moraleja parece cristianizarse en la segunda. En la primera era el dolor del padre ("el hombre era estatua. Por las mejillas de esa estatua, dos lagrimones rodaron, turbios, hasta la barba temblorosa") lo que conmovía al médico ("en los ojos del doctor se diría que un vidrio de luz, un reflejo de agua titilaba como una estrella"), Ilevándole a reanudar la operación sin más explicaciones. La versión definitiva, además de introducir un momento de duda en el obrero ("sin saber si el doctor Zutano hablaba en serio o bromeaba"), hace más explícita su búsqueda de la compasión (“¡Pero, señor, el niño! ¡Que está abierto, que está ahí como muerto! ¿Señor, por el alma de quien tenga en el otro mundo!"). La trascendencia de esa apelación le permite al cirujano argumentar de una manera que, a mi juicio, parecería poco compatible con el pensamiento del médico coruñés que acaso protagonizó la anécdota: “¿Crees tú en el otro mundo? (...) ¿Crees en el alma? Mira, lo dudo, porque os tienen mareados y ya ni sabéis lo que creéis..."

El final del relato es también diferente en cada una de sus dos versiones: la primera, tras resumir la intervención, pone en labios del doctor -que anuncia sus próximas visitas- la enseñanza del caso:

Y, bruscamente, velozmente, se inclinó sobre el niño, y cinco minutos después, victorioso, depositaba en la jofaina la masa del tumor extirpado. Luego, el lavatorio, el cosido vendaje, un primor, en su género...

-A ver si puede ir a su casa en un coche de punto. Yo lo pago... Ya iré a ver cómo sigue. Dentro de ocho días cicatrizó eso. Ahora lárgate, que es tarde, y los obreros que no holgamos necesitamos el cocido a su hora....

La versión definitiva amplía las súplicas del padre, cuando percibe el riesgo que amenaza a ese niño que parece agonizar. En cambio, suprime los detalles quirúrgicos, la promesa de las visitas (pues el médico ya las había anunciado en la consulta matinal, antes de la operación: "yo paso a verle unos días, hasta que no necesite más visitas"); y, lo que es más significativo, desaparece el irónico comentario que explicitaba la moraleja: 
Más blanco que la cera el padre; empezando a entender que aquello iba de veras, que su hijo se moría, abierto, despedazado, con el estertor que le causaba el anestésico -echándose de rodillas, gimiendo, imploró:

-¡Señor! ¡Que es mi hijo! ¡Que soy su padre, señor! ¡Su padre!

-¡Eso te vale, zángano! -murmuró el médico-; y, dando un empujón ligero al hombre para desviarlo, y encogiéndose de hombros, continuó y remató brillantemente la operación emprendida.

En conclusión: tras una lectura detenida de las dos versiones del relato, parece razonable suponer que las abundantes y significativas modificaciones en el texto "Auténtico", aparecido en Caras y Caretas en octubre de 1910, para su inclusión en el volumen Cuentos trágicos (1912) con el título "Argumento", mostrarían que la autora quiso escamotear o difuminar las referencias al modelo del médico protagonista de aquella historia, don Ramón Pérez Costales, que había fallecido en enero de 1911.

\section{BIBLIOGRAFÍA}

Bravo-Villasante, Carmen (1962): Vida y obra de Emilia Pardo Bazán, Madrid, Ediciones de la Revista de Occidente.

Barreiro Fernández, Xosé Ramón (coordinador) (2003): Parlamentarios de Galicia: biografías de deputados e senadores (1810-2003), Santiago de Compostela, Parlamento de Galicia e Real Academia Galega, $2^{\text {a }}$ ed. corrixida e aumentada.

Clemessy, Nelly (1973): Emilia Pardo Bazán, romanciére (La critique, la théorie, la pratique), Paris, Centre de Recherches Hispaniques.

De la Fuente Monge, Gregorio (2009), "Ramón Pérez Costales": Diccionario Biográfico de la Real Academia de la Historia, Madrid, Real Academia de la Historia; accesible en: http://dbe.rah.es/biografias/14114/ramon-perez-costales

Fraga Vázquez, Xosé A. (2013): "Ramón Pérez Costales", en Álbum da Ciencia. Culturagalega.org. Consello da Cultura Galega; accesible en: http://culturagalega.gal/ albumdaciencia/detalle.php?id=481\&autor=Ram\%F3n\%20P\%E9rez\%20Costales

González Herrán, José Manuel (2010): “Once cuentos de Emilia Pardo Bazán, recuperados de la revista Caras y Caretas (Buenos Aires, 1909-1916)", Siglo diecinueve (Literatura Hispánica), nº 16, pp. 241-290.

(2013): "Variantes textuales en los cuentos de Emilia Pardo Bazán: el volumen En tranvía (Cuentos dramáticos)": E. Penas (ed.), Perspectivas críticas para la edición de textos de literatura española, Santiago de Compostela, USC editora, pp. 211-234.

(2014): "La cuestión social en algunos cuentos de Emilia Pardo Bazán": J.

Urrutia y D. Thion Soriano-Mollá (eds.), De esclavo a servidor. Literatura y sociedad (1825-1930), Madrid. Biblioteca Nueva, pp. 159-180.

Hernández Segura, Amparo (2001): "Semblanzas republicanas. D. Ramón Pérez Costales. Apuntes para un ensayo": VV.AA. El republicanismo coruñés en la Historia. A Coruña, Concello de A Coruña, pp. 207-214. 
Leirós Fernández, Fernanda (2010-2011): “Unha dedicatoria de Ramón Pérez Costales a Emilia Pardo Bazán", La Tribuna. Cadernos de Estudos da Casa-Museo Emilia Pardo Bazán, 8, pp. 247-252.

Moreno González, Xoan Manuel [firmado: X.-M.M.G.] (1974): "Ramón Pérez Costales": Gran Enciclopedia Gallega, volumen XXIV, pp. 187-189.

Murguía, Manuel, (1911): "Necrología. Don Ramón Pérez Costales", Boletín de la Real Academia Galega, no 43, pp. 170-172.

Pardo Bazán, Emilia (1887): "Prólogo" a R. Pérez Costales, Perucho, La Coruña, Andrés Martínez Editor, pp. ix-xvi.

[1891]: La piedra angular, Obras Completas, tomo II Madrid, edición de la autora, sin año. Cito por Obras Completas: vol. III, (novelas), ed. D. Villanueva y J. M. González Herrán, Madrid, Biblioteca Castro, 1999.

[1894 y 1896]: Adán y Eva (Ciclo). Doña Milagros. Memorias de un solterón, Obras Completas, tomos XI y XIV, Madrid, edición de la autora, sin año. Cito por Obras Completas: vol. III, (novelas), ed. D. Villanueva y J. M. González Herrán, Madrid, Biblioteca Castro, 1999.

(1910): “Auténtico", en Caras y Caretas, n 630, 29 de octubre de 1910; recogido en González Herrán 2010, págs. 257-259.

(1912): "Argumento", en Cuentos trágicos, Madrid, Renacimiento, s. a. [1912]; recogido en Obras Completas: vol. X (Cuentos), ed. D. Villanueva y J. M. González Herrán, Madrid, Biblioteca Castro, 2005, págs. 517-521.

Pérez Costales, Ramón (1887): Perucho. Poema en seis cantos, con un prólogo de Emilia Pardo Bazán, La Coruña, Andrés Martínez Editor.

Santiso Rolán, Xulia y Manuel González Prieto (2015): Emilia Pardo Bazán y Pablo Ruiz Picasso, A Coruña, Real Academia Galega / Casa-Museo Emilia Pardo Bazán.

Varela Iglesias, José Luis (2001): "Emilia Pardo Bazán: Epistolario a Giner de los Ríos", Boletín de la Real Academia de la Historia, CXCVIII. 2, pp. 327-390; continuación en: Boletín de la Real Academia de la Historia, CXCVIII. 3, pp. 439-506.

Varela Jácome, Benito (1973): Estructuras novelísticas de Emilia Pardo Bazán, Santiago de Compostela: C.S.I.C.

Ventureira Novo, Rubén y Elena Pardo Antequera (2019): Picasso, Ramón Pérez Costales y el Colegio de Médicos de A Coruña, A Coruña, Colegio Oficial de Médicos da Coruña. 


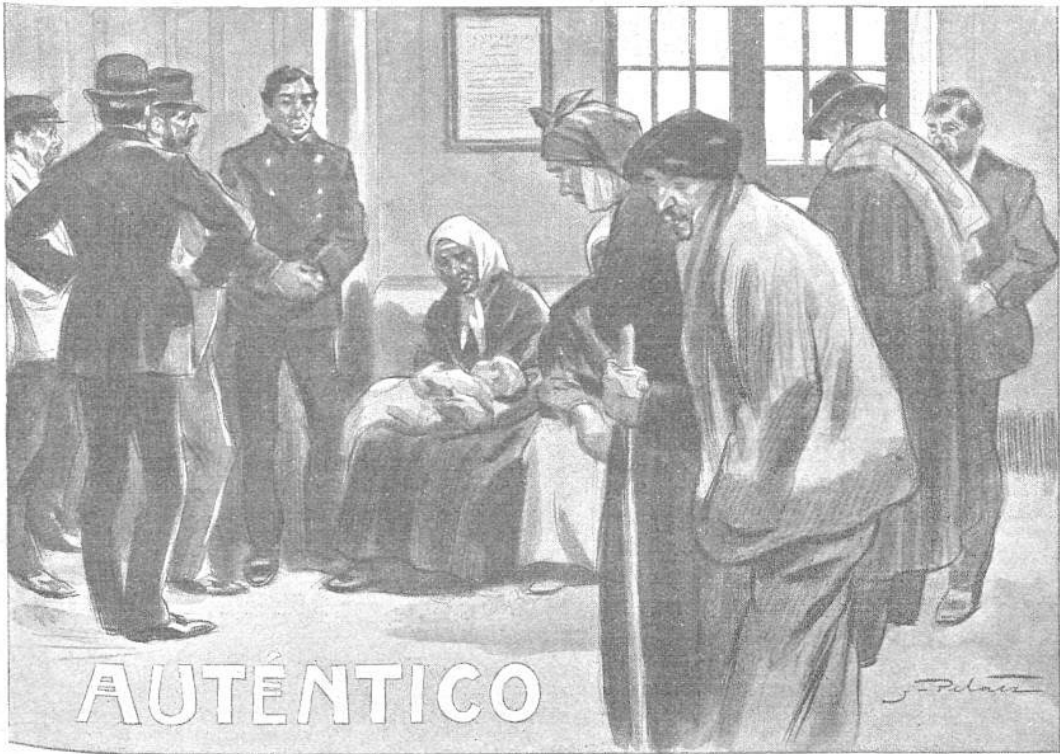

Para "Caras y Caretas".

¿Quién no le conoce, no en la ciudad, en las cuatro provincias, y aun más allá, ultrapuertos? La fama de su ciencia, ó más bien de sus geniales aciertos y de sus rarezas típicas, va adquiriendo proporeiones de leyenda. Se tiene en fianza, fe eiega, y también inspira terror. ¡No por os honorarios modestos que reelama! Eso, nunea; pues para el doctor. llamémosle el doctor Z tano,-existen eiertas zarandajas, como la conciencia, el alma, la otra vida, y por conseenencia, la moral médiea más escrupulosa. Infunde miedo por sus desplantes, por sus ironias, por su segunda vista, de escocés, por sus burlas, por sus regaños, por su originalidad, por lo imprevisto de sus pres. eripeiones. La gente, al entrar allí, se palpa con zozobra.

- $\mathrm{M}_{\mathrm{e}}$ ordenará, para curarme la ieterieia, que the corte un brazo? Me hará afeitar al rape? ¿Arrancarme las patillas?

Abre el doctor su consulta á las ocho en in vierno, pero desde las cinco hay gente en su ace, en su portal, en los rellanos de su esealera $y$, si el fámulo consintiese, en su antesala. A entrar en ella, se dividen los elientes: en un apoSento, los de pago; en otro, los pobres. Por nno de estos empieza invariablemente la consulta. Después, un rico. $Y$ así alternan, hasta que rendido una cansancio, á horas irregulares, el médico da igu orden furibunda. "A largarse todos". Con igual ealma y con interés en cada easo renovado, meruta el doetor las peludas orejas de un astros mendigo, y la dentadura brillante de oralería de ina gentil damisela; porque el doctor reconoce ciempre dientes y ódes, y una de sus milagrerís extraste en haber curaclo hasta casos de locura, extrayendo, entre eareajadas de triunfo, un tapon de cera que, desde el conducto auditivo, comprimia el cerebro.

(C) Biblioteca Nacional de España ${ }^{\mathrm{y}}$ estantes de esperanza mis-
El doctor es expeditivo. Operación que eree ne: cesaria y pueda realizar en su casa, no la difiere un minuto. Su aceión rápida forma parte de su genialidad. Además, eree que generalmente son una farsa los preparativos, las precauciones...

- Bah, bah! Farolerías.

Lo más eurioso de un hombre tan digno de estitdio en su psicología, son acaso sus ideas políticas. y sociales. Para comprenderlas habria que retroceder hasta aquellos misticos franciscanos, del período primitivo de la Orden, humildes hermanillos, mendieantes con alegría, enamorados de la pobreza $y$ de todo el que sufre, $y$ prontos á reprender con fuego satírico los defectos del Papa. El doctor Zutano en nada se parece á un reaceionario clásico. Amparador de los desheredados, it toda hora les tiene dispuesto el socorro de su ciencia. De los poderosos no hace caso alguno. A las damas emperifolladas las pone como un renegrido trapo. No le impresionan, al contrario, le provocan cierto espíritu agresivo y frondista los personajes políticos y los plutócratas. A la aristocracia de sangre no la mira tan mal, porque, hijo del pueblo, un marqués le ayudó en su carrera. Sin embargo, sospecho que no eree en sangres azules. Para él, los hombres son hombres tan sólo; hombres que padecen. Iguales todos, con la única igualdad suprema; carne doliente ahora, polvo y ceniza mañana... Y la farándula política inspira desprecio al doctor, venga de arriba 6 venga de abajo. Sólo se inclina ante dos cosas sagradas: el dolor y la maternidad. A las madres, las sueña fuera de lo humano, 6 más adentro de lo humano tal vez; fieras de amor, angeles tiernos. y terribles. Los padres también han de verter la entraña en el suelo, si hace falta, por su ería. Y el doctor no tiene hijos.

Un dia, en aquella antesala donde se oían cu- 
teriosa, donde serpea el sutil estremecimiento de lo maravilloso - pudo verse un grupo como muchos: un obrero de unos cuarenta y pico de años, fornido, de remendada blusa, sosteniendo á un uiño de unos diez 6 doce, que semejeha, más que enfermo, moribundo. De la garganta entrapajada de la eriatura salía un estertor roneo, de asfixia, y su eabeza, inerte, se apoyaba en el hombro del padre. Este, apretando los dientes para contener lit impaciencia, aguardaba, deseoso de aniquilar de un puñetazo á los que le aventajaban en turno. Por fin, el suyo llegó. Llevando al rapaz en peso, por los sobacos, el jaque penetró en el gabinete, y se detuvo, sobrecogido de respeto, des lumbrado por las fulguraciones de acero que despedia, en las vitrinas, el instrumental, hericlo por el sol.

El doctor avanzaba, de un salto ligero...

$Y$. sin preguntar, im poniendo las manos al chico, decidia:

- Bueno, un tumor interior, en la gargan. ta... ¿Cómo se hay deseuidado tanto? F su padre? Pues pareee su padrastro.

- Yo... Decia el otro médico... Diéron. ic un emplasto..

- Diéronle un cuer. no... ; icon perdón! A ver, á ver... La operación... ien seguida! E] chiquillo se ahoga Rascóse la greña el padre.

$-\mathrm{Y} \ldots$ me costari muchos cuartos, ; señor?

- Le costará un padrentuestro por el alma del marqués de San Sabas... Al avio. SSoy ciego, para no ver que no es nsted millonario?

- Soy un pobre

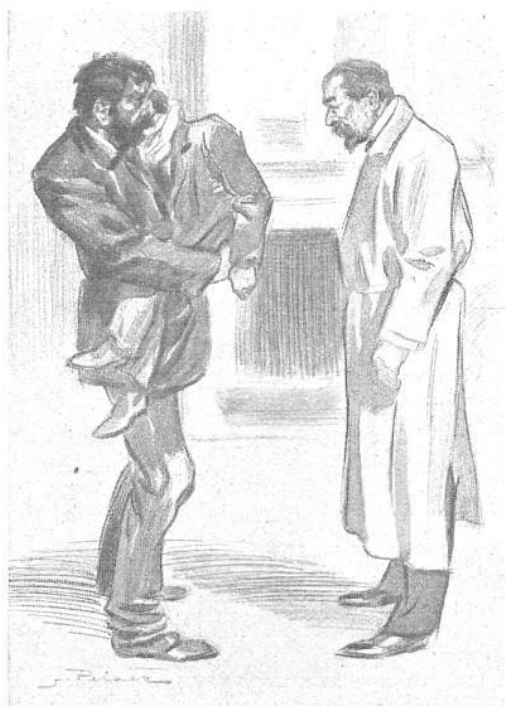

Con manos diestras, fué levantando los gniñapos fétidos que envolvian el cuello del enfermo. bajando la camisa, despojándole del raído ehaque. tón. Las carnes demacradas y sucias aparecian.

- Estando en huelga, v no teniendo qué ha cer, bien pudiste fregar a tu cría, aunque fuest con estropajo...

El padre callaba, a la defensiva. Sabia que ne convenia irrifar á aquella pólvora de métlieo, que operaria á su chico do balde.

Campanilleó el doctor.

- El practieante, en seguida..

Un cuarto de hora después, el niño, anestesiatio, yacía sobre la mesa operatoria. El doctor, se guro, tajando firme, aislaba, buseaba el neoplas. ma, para erradicarlo como una planta venenosi. El padre, en pie, enelavijaba los dedos de una mano en el dorso de la otra, hineando sin notarlo las uñas, erecidas porr la holganza. Sudaba frio. La eriatur: iha á morir degollada... iCuánta sangre! ¿Qué hondo entraba e! acero!

De súbito se paró el doctor.

- Está ya, señor? ¿Está ya?

- iQué ha de estar! Tenemos para media hora. Pero, no sigo Sirbes lo que pasa: Me declaro en huelga. — ¿ Fh? ¿Qué diee - gritó el obrero at nito.

- ¿No hablo elaro: Que en huelga estoy.

-Y... i el niño? ¿ Mi chiquillo?

- La huelga es un derecho...

El hombre era esta tua. - Por las mejillas de esa estatua, dos la grimones rodaron, turbios, hasta la barba tem. blorosa.

Sólo acertó á implorar:

— Señor... señor... iQne soy su padre!

A su vez, en los ojos del doctor se diría que un vidrio de luz, un reflejo de agua titilaba co uo una estrelia.

- isuerte tienes en no ser su tío!

$Y$, hruscamente, velozmente, se inclino sohre el niño, y cinco minutos después, vietorioso, de positaba en la jofaina la masa del tumor extirpado. Luego, el lavatorio, el cosido vendaje. un primor, en su género...

- A ver si puede ir a su casa en un eoche d. yunto. Yo lo pago... Ya iré á ver como siguc. Dentro de ocho dias cieatrizó eso. Ahora lár gate, que es tarile, y los obreros que no holga. mos neeesitamos el cocido á su hora...

Emilia PARDO BAZĀN.

Dib. de Peláes. 